\title{
sciendo
}

\section{LinkedIn, a vocational social network, as a tool for promotion in selected healthcare service providers}

\author{
Jiří BEJTKOVSKÝ \\ Tomas Bata University in Zlín, Czech Republic \\ bejtkovsky@utb.cz
}

\begin{abstract}
The use of social media platforms and other online tools in the human resource management area has become a common part of the HR manager work. Today, the main aim of every corporation is to have the right employees at the right time and in the right job positions. The main objective of this research paper was to identify whether the size of the selected healthcare service providers influences the existence of a profile on the vocational social network LinkedIn, the active use of the vocational social network LinkedIn for sharing a job vacancy and the active use of the vocational social network LinkedIn for promoting or building the employer brand. Three research hypotheses were defined. The collection of research data was carried out from October 2018 to January 2019. The conducted research has shown that the size of the selected healthcare service provider does not affect the active use of the vocational social network LinkedIn and sharing a job vacancy, promoting or building the employer brand.
\end{abstract}

Keywords: healthcare service provider, LinkedIn, professional social network, social media platforms.

Please cite the article as follows: Bejtkovský, J. (2021), "LinkedIn, a vocational social network, as a tool for promotion in selected healthcare service providers", Management \& Marketing. Challenges for the Knowledge Society, Vol. 16, No. 3, pp. 286-299, DOI: 10.2478/mmcks-2021-0017.

\section{Introduction}

The turbulent development of social media platforms over the past decade has also influenced the area of the human resources management in many ways, both positively and negatively. As a result, scientists and experts have tried to investigate the diverse ways in which social media platforms affect corporations. Social media platforms have a positive and/or negative impact not only on human resources management, but also on HR marketing, promotion and PR of the corporation, psychology, marketing, sociology, employer branding, management and many other scientific disciplines or corporate areas (Kluemper, Mitra \& Wang, 2016).

According to Gerard (2012), creating social media platforms can lead, besides other things, to a first job or to professional development, and technology can improve the success of individual and corporate efforts.

Social media platforms are usually characterized as a system with a set of social participants and a set of social relationships that determine how these participants connect to each other (Wasserman \& Faust, 1994). 
According to Ruggieriet al. (2019), digital platforms provide the opportunity to connect people, corporations and resources to facilitate basic business-to-people interactions.

Çitlak, Dörterler \& Doğru (2019) say that social media platforms such as LinkedIn, Facebook, Instagram, Google+, Twitter and others have become an integral and active part of people's lives. Thanks to social media platforms, people interact with each other via the Internet. They gain many benefits, such as creating their own groups, communicating on different areas of interest, and having the opportunity to establish many professional and professional contacts.

According to Davidsson \& Honig (2003), social media platforms and human capital indexes bring various kinds of opportunities to a business where one cannot compensate for another.

In this context, Stokes et al. (2019) say that social media platforms are an emerging tool used by scientists; however, there is limited information on its implementation for the specific recruitment of new employees.

Social media platforms can be defined as web-based services that allow individuals or corporations to (1) build a public or semi-public profile, (2) formulate a group of other users with whom they share a connection, and (3) view and browse their list of connections, photos, videos and so (Boyd \& Ellison, 2007).

Building upon the relevant literature and secondary information sources, the main aim of this research paper was to determine whether the size of the selected healthcare service providers influences (1) the existence of a profile on the vocational social network LinkedIn, (2) the active use of the vocational social network LinkedIn for sharing a job vacancy and (3) the active use of the vocational social network LinkedIn for promoting or building employer brand. The research paper follows a standard structure, i.e., defining the literature review; followed by clarifying the methodology, research aims and data. The next section provides a presentation of the results and a discussion. The last part contains the conclusion of the research paper at hand.

\section{Literature review}

\section{LinkedIn - a vocational social network}

LinkedIn was established in the living room of co-founder Reid Hoffman in 2002 and was officially launched on May 5, 2003. LinkedIn is the largest network of professionals in the world, with more than 645 million members from 200 countries and regions around the world. LinkedIn's vision is to create an economic opportunity for every member of the work contingent in the world by building the world's largest network in its economic graph form. LinkedIn's mission is to connect professionals around the world to be more productive and more successful in their careers (LinkedIn, 2019; retrieved from https://press.linkedin.com/about-linkedin).

LinkedIn is a significant and great tool to keep up to date with the latest job-related news, a way to learn about new hires joining a corporation or human resources on a new team (Brooks, 2019).

The vocational social network, LinkedIn, has become an important and interesting tool for building the professional, social and personal know-how of each person, as well as his or her identity and reputation (Kietzmann et al., 2011). 
In this context, Rapanta \& Cantoni (2017) say that, unlike other social media platforms, such as Twitter, Instagram, Facebook, and others social media platforms that focus on the networking aspects of the network as such, "keep in contact", LinkedIn is the most influential web-based tool for professional use.

On the other hand, Kashi et al. (2016) state that in recent times, social media platforms such as LinkedIn, Facebook, and Twitter have become increasingly popular among organizations and HR managers, HR specialists and recruiters as a way to identify, attract, and recruit potential human resources.

According to Banerji \& Reimer (2019), unlike profiles on other social media platforms, LinkedIn's profile is like an online CV aimed at professionals who connect with other (HR) professionals to create an active and communicating group of human resources. The social media platform LinkedIn offers information about the educational and professional background of a user.

Each LinkedIn profile has the following sections: (1) photograph, (2) headline or job position, (3) profile summary, (4) work experience of a person, (5) volunteer activity, (6) project activity, (7) language skills, (8) obtained certificates, (9) publications, (10) education, (11) discussion comments, papers and posts, (12) recommendations, (13) endorsed expertise and skills, (14) hobbies and vocational interests, (15) and awards or honors. The sections in the LinkedIn profile, the accuracy of the relevant volunteer experience and work experience and the type of photograph used contribute to the vocational identity of each LinkedIn user. The type, significance and number of endorsements, recommendations and connections along with the entire LinkedIn profile being complete, information about the LinkedIn user for the readers - the recruiters, HR specialists, HR managers and/or headhunters (Bangerter, Roulin \& König, 2012).

In this context, Papacharissi (2009); Trusov, Bucklin \& Pauwels (2009) say that LinkedIn, as a social media platform, is used in different contexts and for various aims or intentions, for example (1) for promotion and PR of the corporation, (2) for HR campaigns, (3) for HR marketing, (4) for recruiters, HR specialists and/or headhunters who can looking for a suitable candidate for a job among a large number of potential employees, (5) for connecting and communicating with different professionals, not only in HR area, and sharing diverse information, creating different discussion forums, groups, and so on.

According to Donath (2007); Ellison, Steinfield \& Lampe (2007), it can be said that LinkedIn supports connection sharing, social capital generation and effective communication.

In this context, Breeding (2009); Trusov, Bucklin \& Pauwels (2009) say that LinkedIn provides possibilities to offer new content and new connections.

The users of the vocational social network LinkedIn usually connect to their work network and use this platform to strengthen and maintain a contact list for people they know and trust in their work (Papacharissi, 2009).

Most research or research projects and studies on social media platforms are Facebook-oriented, but there are very few studies on LinkedIn as a tool of the recruitment process. However, users of LinkedIn report the greatest information advantages, so business networks certainly deserve more research attention (Utz, 2016).

According to Stokes et al. (2019), among the strengths and benefits of recruiting with LinkedIn include the cost-effectiveness, the speed of recruitment process and the effects of snowballing. 
In this context, Vardarlier \& Ozsahin (2021) say that the recruiters, HR specialists, HR managers often use social media tools for recruitment processes and prefer LinkedIn in all HR management processes, regardless of business size or area.

Kwok \& Muñiz (2021) also say that LinkedIn is the most preferred social media tool for recruitment processes, and social media tools play an ever-increasing role in promoting a job vacancy or a new job and in the recruiting and selection process.

On the other hand, Silva et al. (2017) state that HR managers and recruiters only use the vocational social network LinkedIn as a complement to the recruitment process.

\section{Promotion as a tool of HR marketing and Employer brand}

Promotion as a tool of HR marketing can be perceived as a comprehensible presentation of the job offer and of the corporation on the labor market. This presentation of the job offer must be engaging to stimulate and attract the attention of potential employees. For effective job promotion, it is essential that the presentation has the necessary information for a potential candidate. This information should include (1) facts about the job position, (2) a short description of the work duties, activities and responsibilities required by the job position, (3) work experience, (4) language skills, (5) educational requirements, (6) skills, (7) qualifications of potential employee, (8) as well as personality requirements of the potential employee (Antošová, 2005).

Nowadays, the labor market is a very competitive place and the employer brand allows individual corporations to differentiate themselves from other corporations on the market (Strenitzerová, 2016). In this context, Wroblowská (2019) says that the employer brand plays an important role for the successful existence of the corporation in the current global and competitive environment.

The building a product, service or employer brand is a long-term activity and it also extends to the social media world (Bačík et al., 2018),

According to Barrow \& Mosley (2011), the employer brand forms the name, reputation and image of the corporation as an employer, and its value proposition for its human resources.

In this regard, Ambler \& Barrow (1996); Berthon, Ewing \& Hah (2005) say that the employer brand offers functional, psychological and economic benefits that the corporation provides not only to its employees but also to its surroundings.

Employer brand includes nominal, useful and symbolic attributes and variables of the work and of the corporation as perceived by existing staff (internal employer brand internal marketing concept) and potential employees (external employer brand - external marketing concept). Nowadays, the employer brand is very significant and substantial for every corporation and it should not be underestimated or neglected (Franca \& Pahor, 2012; Soulez \& Guillot-Soulez, 2011; Srivastava \& Bhatnagar, 2010). The motivated, qualified, satisfied and loyal human resources form the employer brand in today's highly competitive environment (Anyim Chukwudi, Olusoji \& Aremu Nuha, 2018).

Based on the relevant literature and secondary information sources, it can be said that the research assumptions are focused on finding out whether the vocational social network LinkedIn is used by healthcare service providers in the field of human resources management. However, it must be said that in the context of healthcare service providers, there is very limited research on the issue of the vocational social network LinkedIn. 
This fact is also confirmed, among other things, by Kashi et al. (2016), who claim that the dearth of the research, papers or studies in the field calls for more theory-driven and scholarly research to investigate key factors of a successful organizational-level adoption.

\section{Methodology}

Today's labor market is characterized by a lack of skilled human resources. Therefore, the corporate management must use not only offline tools but also online tools to inform, stimulate and seek to recruit employees to work in their corporation.

This research paper thus focuses on the vocational social network, LinkedIn, as a promotion tool. The research study was conducted from the perspective of the selected healthcare service providers in the Czech Republic.

The main aim of this research paper was to determine whether the size of the selected healthcare service providers influences (1) the existence of a profile on the vocational social network LinkedIn, (2) the active use of the vocational social network LinkedIn for sharing a job vacancy and (3) the active use of the vocational social network LinkedIn for promoting or building employer brand.

Secondary and primary information sources were used for processing this research study. The theoretical framework was prepared using secondary information sources through scientific articles, scientific monographs and scientific journals from the Scopus database and the Web of Science database. These sources of information were mainly targeted by the vocational social network LinkedIn and also by social media platforms.

In particular, the quantitative marketing research was implemented to obtain primary information sources. A structured questionnaire survey was used as a research technique. This questionnaire survey was printed as well as in electronic form. The ethical aspects of the research as well as the anonymity of the respondents were respected in the research survey. In this research paper, only certain research results are discovered and presented.

Three research hypotheses ( $\mathrm{H} 1, \mathrm{H} 2$ and $\mathrm{H} 3$ ) were formulated in the context of the theoretical framework and synthesis of information sources and facts. The hypotheses are determined as follows:

The research hypothesis 1 (H1): There is a statistically significant relation between the existence of a profile on the vocational social network LinkedIn and the size of the selected healthcare service provider.

The research hypothesis $2(\mathrm{H} 2)$ : There is a statistically significant relation between the active use of the vocational social network LinkedIn for sharing a job vacancy and the size of the selected healthcare service provider.

The research hypothesis 3 (H3): There is a statistically significant relation between the active use of the vocational social network LinkedIn for promoting or building employer brand and the size of the selected healthcare service provider.

In terms of the research sample of respondents, the selected healthcare service providers were addressed. These healthcare service providers were located only in the Czech Republic. This fact is based on previous research cooperation with these healthcare service providers in the Czech Republic.

A pilot testing of a questionnaire survey was carried out before quantitative marketing research. The main objective of the pilot testing was to find out the correct understanding of the questions in the questionnaire survey. The pretesting was conducted 
in the fourth quarter of 2018 on a sample of eight respondents. The collection of research data was carried out from October 2018 to January 2019.

For the purposes of the questionnaire survey, the respondents were employees of the selected healthcare service providers in the Czech Republic. These respondents are responsible for human resources management area in their healthcare organization. Thus, it was about HR leaders, HR employees, HR managers or HR specialists. A total of fifty-eight correctly completed questionnaires were used to verify the three research hypotheses.

The descriptive statistics tools (absolute frequencies and relative frequencies) were used to analyze the ascertained research data. Pearson's statistical method of the Chisquare test was implemented to confirm or reject the proposed hypotheses ( $\mathrm{H} 1, \mathrm{H} 2$ and H3). The Chi-square test is based on the dependence measurement. The Chi-square test identifies whether there is a relation between statistical characters. This means that the existence of certain A variables can determine the probability of existence of certain B values. The zero hypothesis is rejected if the $\mathrm{p}$-value is lower than the selected significance level (usually 0.05 , i.e. $5 \%$ ). This means that the difference between the abnormalities found in the sample and the expected abundances is too large to be the result of random selection, i.e., it is statistically significant.

The statistic formula for the Chi-square test is: $X^{2}=\sum_{i=1}^{r} \quad \sum_{j=1}^{C} \frac{\left(o_{i, j}-E_{i, j}\right)^{2}}{E_{i, j}}$, where (C)statisticssolutions.com, 2021): $X^{2}=$ Chi-square test of Independence; $\mathrm{O}_{\mathrm{i}, \mathrm{j}}=$ observed value of two nominal variables; $E_{i, j}=$ expected value of two nominal variables. The degree of freedom is calculated by using the following formula: $D_{f}=(r-1) \cdot(c-1)$, where: $D_{f}=$ degree of freedom; $r$ = number of rows; $c=$ number of columns.

The research results were analyzed and subsequently processed through the Microsoft Excel 2013 software program and the IBM SPSS Statistics software, version 23.

\section{Results and Discussion}

In the context of the theoretical framework focusing on vocational social network LinkedIn and social media platforms, three research hypotheses (H1, H2 and H3) were formulated. The Pearson's Chi-square test, Microsoft Excel 2013 and IBM SPSS Statistics 23 were implemented to confirm or reject the proposed research hypotheses.

A structure of the selected healthcare service providers by the number of the hospital wards is presented in table below (Table 1).

Table 1. The structure of the selected healthcare service providers in the Czech Republic by the number of the hospital wards

\begin{tabular}{|c|c|r|}
\hline $\begin{array}{c}\text { Number of hospital } \\
\text { wards (beds) }\end{array}$ & $\begin{array}{c}\text { The absolute frequency } \\
\text { (n) }\end{array}$ & $\begin{array}{c}\text { The relative frequency } \\
\text { (\%) }\end{array}$ \\
\hline $0-99$ & 20 & 34.48 \\
\hline $100-199$ & 9 & 15.52 \\
\hline $200-299$ & 4 & 6.90 \\
\hline $300-399$ & 6 & 10.34 \\
\hline $400-499$ & 2 & 3.45 \\
\hline $500-599$ & 3 & 5.17 \\
\hline $600-699$ & 4 & 6.90 \\
\hline $700-799$ & 1 & 1.72 \\
\hline
\end{tabular}

Vol. 16, No. 3, pp. 286-299, ISSN 2069-8887| Management \& Marketing. Challenges for the Knowledge Society 


\begin{tabular}{|c|c|r|}
\hline $800-899$ & 2 & 3.45 \\
\hline $900-999$ & 3 & 5.17 \\
\hline $1000+$ & 4 & 6.90 \\
\hline Total & $\mathbf{5 8}$ & $\mathbf{1 0 0 . 0 0}$ \\
\hline
\end{tabular}

Source: Authors' own research results

The table (Tab. 1) introduces the structure of the selected healthcare service providers by the number of the hospital wards.

The research hypothesis 1 (H1): There is a statistically significant relation between the existence of a profile on the vocational social network LinkedIn and the size of the selected healthcare service provider.

$\mathrm{H} 0$ : There is no correlation between the existence of a profile on the vocational social network LinkedIn and the size of the selected healthcare service provider.

The data characterizing the research hypothesis 1 (H1) are presented in the table below (Table 2).

Table 2. The verification of the research hypothesis H1 by means of the Pearson's Chi-square test

$\mathrm{H} 1$ : There is a statistically significant relation between the existence of a profile on the vocational social network LinkedIn and the size of the selected healthcare service provider.

The statistical method

Pearson's Chi-square test

Chi-square

11.234

df

p-value .340

Source: Authors' own research results

The p-value of the Pearson Chi-square independence test is equal to 0.340 , which represents the result of the verification of the research hypothesis H1. Unfortunately, this result is higher than the specified limit value of 0.05 . On this basis, it can be said that the $\mathrm{HO}$ hypothesis is not rejected on the significance level of $5 \%$. Thus, there is no statistically significant relation between the existence of a profile on the vocational social network LinkedIn and the size of the selected healthcare service provider. The selected healthcare service providers have a profile on the vocational social network LinkedIn regardless of whether they are a small, a medium or even a large selected healthcare service provider.

The research hypothesis $2(\mathrm{H} 2)$ : There is a statistically significant relation between the active use of the vocational social network LinkedIn for sharing a job vacancy and the size of the selected healthcare service provider.

H0: There is no correlation between the active use of the vocational social network LinkedIn for sharing a job vacancy and the size of the selected healthcare service provider.

The data characterizing the research hypothesis $2(\mathrm{H} 2)$ are presented in the table below (Table 3).

Table 3. The verification of the research hypothesis $H 2$ by means of the Pearson's Chi-square test

$\mathrm{H} 2$ : There is a statistically significant relation between the active use of the vocational social network LinkedIn for sharing a job vacancy and the size of the selected healthcare service provider.

\begin{tabular}{|c|c|c|c|} 
The statistical method & Chi-square & df & p-value \\
\hline Pearson's Chi-square test & 7.752 & 10 & .653 \\
\hline
\end{tabular}


When considering a dependence of the relation between the active use of the vocational social network LinkedIn for sharing a job vacancy and the size of the selected healthcare service provider, the p-value of the Pearson Chi-square independence test is higher than the defined level of significance $(\alpha=0.05)$. The result of the verification of the research hypothesis $\mathrm{H} 2$ shows that the null hypothesis (H0) of independence was not therefore rejected on the significance level of $5 \%$. In this context, it can be said that there is no statistically significant relation between the active use of the vocational social network LinkedIn for sharing a job vacancy and the size of the selected healthcare service provider.

The research hypothesis 3 (H3): There is a statistically significant relation between the active use of the vocational social network LinkedIn for promoting or building the employer brand and the size of the selected healthcare service provider.

H0: There is no correlation between the active use of the vocational social network LinkedIn for promoting or building employer brand and the size of the selected healthcare service provider.

The data characterizing the research hypothesis $3(\mathrm{H} 3)$ are presented in table below (Table 4).

Table 4. The verification of the research hypothesis $H 3$ by means of the Pearson's Chi-square test

H3: There is a statistically significant relation between the active use of the vocational social network LinkedIn for promoting or building employer brand and the size of the selected healthcare service provider.

\begin{tabular}{c|c|c|c|} 
The statistical method & Chi-square & df & p-value \\
\hline Pearson's Chi-square test & 5.425 & 10 & .861 \\
\hline
\end{tabular}

Source: Authors' own research results

As it is presented in the table (Table 4), the research finding regarding the verification of the research hypothesis H3 shows that the p-value of Pearson's Chi-square test of independence is 0.861 . This value is higher than the standard limit value of 0.05 . Therefore, on the basis of this finding, the $\mathrm{HO}$ hypothesis is not rejected on the significance level of $5 \%$. In this case, it can be deduced that there is no statistically significant relation between the active use of the vocational social network LinkedIn for promoting or building employer brand and the size of the selected healthcare service provider.

This research study provided three important and interesting findings. The first is that there is no statistically significant relation between the existence of a profile on the vocational social network LinkedIn and the size of the selected healthcare service provider. The second interesting finding is that there is no statistically significant relation between the active use of the vocational social network LinkedIn for sharing a job vacancy and the size of the selected healthcare service provider. Finally, the third finding is that there is no statistically significant relation between the active use of the vocational social network LinkedIn for promoting or building employer brand and the size of the selected healthcare service provider. It can therefore be stated that the selected healthcare service providers (1) have a profile on the vocational social network LinkedIn, (2) actively use the vocational social network LinkedIn for sharing a job vacancy and (3) actively use the vocational social network LinkedIn for promoting or building employer brand regardless of whether they are a small, a medium or even a large selected healthcare service provider. 
It is worth mentioning that although the implementation of social media platforms in the human resource management area is becoming commonplace, there is little empirical research on this phenomenon (Melão \& Reis, 2020).

Research studies and projects have evolved along with the development of an online environment and computer-mediated communication (Rosen, Barnett \& Kim, 2011).

The research studies focused on social media platforms generally monitor their impact on gender (Hjorth \& Kim, 2005), ethnicity, national identity and race (Fragoso, 2006; Gajjala, 2007), and religion (Nyland \& Near, 2007).

Lenhart \& Madden (2005) found that more than half of the teenagers using the Internet create blog content and share videos, stories and/or photos through social media platforms such as Facebook, Flickr and YouTube and other platforms.

A research analysis by Banerji \& Reimer (2019) found that several factors (promotion factors, human resources management factors, finance factors and other factors) in LinkedIn profiles had a positive impact on the amount of funds raised by startup corporations, which links social networking and business success.

According to research studies by Caers \& Catelyns (2011), HR specialists, recruiters and HR managers use LinkedIn to get more information about potential employees, with 70 $\%$ of the HR specialists relying on LinkedIn to decide which potential employees should be interviewed.

Looking at recruitment, it was found that LinkedIn was used for active recruitment purposes (for active search of potential employees). The addressed respondents are very diverse in their perception of how advantageous LinkedIn can be in this area. Almost as many respondents ( $44.3 \%$ ) claim that they use LinkedIn to find potential employees who fit the vacancies of the corporation than respondents who do not (47.3\%). This difference is mainly due to the intensity with which LinkedIn is used, marking a significant difference $(0.000)$ between frequent and occasional users. This discovery suggests that LinkedIn may indeed have advantages in an active recruitment setting. However, the addressed respondents strongly agree that LinkedIn is not suitable for internal recruitment; in this context, only $5.9 \%$ of the addressed respondents actually used it (Caers \& Catelyns, 2011).

According to Blank \& Lutz (2017); Kluemper, Mitra \& Wang (2016); Landers \& Schmidt (2016), HR specialists or headhunters use LinkedIn to recruit (94.0\%), with $85.0 \%$ of them using it for selection purposes. LinkedIn is slightly more popular for higherincome individuals.

This fact is also presented by Brewer (2018). According to a research study by Brewer (2018), it was found that the vocational social network LinkedIn is the best platform among professional social media platforms for hiring individuals for vacant job roles. This fact was stated by $94.0 \%$ of respondents.

\section{Conclusion}

This research paper deals with the vocational social network LinkedIn and social media platforms. Nowadays, the area of marketing and its connection to the field of human resources management are gaining in importance and necessity. The 21st century corporations not only use classic and standard offline recruitment tools, but also gradually use online tools. A major objective is to have the right employees at the right time and in the right job positions. Therefore, it is necessary to prepare an attractive job offer to draw the 
attention and arouse interest of potential employees. This attractive job offer must describe the job vacancy as the best job position. That is why corporations use online environment such as social media platforms to create and share recruitment videos, various photos, posts, discussion forums, and so on.

In this context Gavurová et al. (2018) say that today's man uses social media platforms to communicate about various events, experiences and activities from personal and professional life. Therefore, it is important that corporate management does not underestimate the importance and strength of social media platforms.

This research contribution dealt with issues related to the vocational social network LinkedIn at the selected healthcare service providers in the Czech Republic. The major goal of the research contribution was to determine whether the size of the selected healthcare service providers influences (1) the existence of a profile on the vocational social network LinkedIn, (2) the active use of the vocational social network LinkedIn for sharing a job vacancy and (3) the active use of the vocational social network LinkedIn for promoting or building employer brand.

The research paper has a typical structure for research work. The first section, Introduction, contains the literature review. This literature review focuses on the vocational social network LinkedIn, social media platforms and employer brand. This section of the research study was processed with the help of research papers presented mainly in the Web of Science database and Scopus database. The second section, Material and Methodology, characterizes the methodology, data collection process and defines three research hypotheses. A structured questionnaire survey was used as research technique. Certain results of the research are presented in this research study. In total, the questionnaire was obtained from fifty-eight respondents. The selected healthcare service providers in the Czech Republic were involved in the research paper. The third part, Results and Discussion, presents information related to the basic research discoveries and confirms or rejects the defined research hypotheses. The Pearson's statistical method of the Chisquare test was implemented to verify the defined hypotheses. This research contribution provides three significant findings. The first discovery is finding that there is no statistically significant relation between the existence of a profile on the vocational social network LinkedIn and the size of the selected healthcare service provider. The selected healthcare service providers have a profile on the vocational social network LinkedIn regardless of whether they are a small, a medium or even a large selected healthcare service provider. The second discovery is that there is no statistically significant relation between the active use of the vocational social network LinkedIn for sharing a job vacancy and the size of the selected healthcare service provider. The third discovery is that there is no statistically significant relation between the active use of the vocational social network LinkedIn for promoting or building employer brand and the size of the selected healthcare service provider.

However, there are also research limitations in the research paper. The first research limitation is the employees' selection principle of the particular healthcare service providers for the purpose of the study. In this case, there were only selected groups of employees among the respondents, namely HR managers. In other words, the study did not include all employees of the selected healthcare service providers. The second research limitation is the scope of the research sample. The presented research sample was not extensive in particular. This could limit the generalization of the research results. The third 
research limitation is the demographic scope of the research - the research study was conducted only in the Czech Republic. The fourth research limitation is the fact that the only method used within the scope of the research was the own questionnaire survey, which could have limited the possibilities of comparing the results with the already conducted research. The fifth and the last research limitation is again the absence of the already implemented studies, research, arguments, and other relevant secondary sources, which would allow further discussion or deeper analysis of other important facts or variables related to social media platforms and the vocational social network LinkedIn.

The originality, value, and contribution to the managerial practice of this research paper lie in the discovery of the fact that the size of the selected healthcare service provider does not affect the active use of the vocational social network LinkedIn and sharing a job vacancy, promoting or building employer brand. This discovery can help, among other things, with the use of the vocational social network LinkedIn in the context of human resource management, especially in the field of the job vacancy or new job promotion, recruitment and selection process.

Nevertheless, this study is among the first to investigate the impact of social media platforms on human resources management in the Czech Republic.

\section{References}

Ambler, T., \& Barrow, S. (1996). The employer brand. The Journal of Brand Management, 04(03), 185-206.

Antošová, M. (2005). Marketing-mix v personalistice. In: Moderní ř́zení, 40(11): 42-44. ISSN 0026-8720. [online]. Retrieved from https://modernirizeni.ihned.cz/c117191720-marketing-mix-v-personalistice/.

Anyim Chukwudi, F., Olusoji, J. G., \& Aremu Nuha, S. (2018). The Effect of Talent Management on Employee Retention: Evidence from Emzor Pharmaceutical Industry, Lagos, Nigeria. Acta Oeconomica Universitatis Selye, 07(02), 07-18. ISSN 1338-6581.

Bačík, R., Fedorko, R., Nastišin, L., \& Gavurová, B. (2018). Factors of communication mix on social media and their role in forming customer experience and brand image. Management \& Marketing. Challenges for the Knowledge Society, 10(02), 1108-1118. DOI: $10.2478 / \mathrm{mmcks}-2018-0026$.

Banerji, D., \& Reimer, T. (2019). Startup founders and their LinkedIn connections: Are wellconnected entrepreneurs more successful? Computers in Human Behavior, 90(01), 46-52. DOI: https://doi.org/10.1016/j.chb.2018.08.033.

Bangerter, A., Roulin, N., \& König, C. J. (2012). Personnel selection as a signalling game.Journal of Applied Psychology, 97(04), 719-738. DOI: http://dx.doi.org/10.1037/a0026078.

Barrow, S., \& Mosley, R. (2011). The employer brand: Bringing the best of brand management to people at work. Hoboken, NJ: John Wiley \& Sons.

Berthon, P., Ewing, M., \& Hah, L. L. (2005). Captivating company: dimensions of attractiveness in employer branding. International Journal of Advertising, 24(02), 151-172.

Blank, G., \& Lutz, C. (2017). Representativeness of social media in Great Britain: investigating Facebook, LinkedIn, Twitter, Pinterest, Google+, and Instagram. American Behavioral Scientist, 61(07), 741-756. DOI: 10.1177/0002764217717559.

Boyd, D. M., \& Ellison, N. B. (2007). Social Network Sites: Definition, History, and Scholarship. Journal of Computer-Mediated Communication, 13(01), 210-230. DOI: https://doi.org/10.1111/j.1083-6101.2007.00393.x. 
Breeding, M. (2009). Social Networking Strategies for Professionals. Computers in Libraries, 29(09), 29-31. ISBN 1041-7915. https://librarytechnology.org/document/14260.

Brewer, S. W. (2018). Come for a job, stay for the socializing: gratifications received from LinkedIn usage. Online Journal of Communication and Media Technologies, 08(04), 345-361, DOI: $10.12973 /$ ojcmt/3956.

Brooks, B. A. (2019). LinkedIn and Your Professional Identity. Nurse Leader, 01(01), 173175. DOI: http://dx.doi.org/10.1016/j.mnl.2019.03.001.

Caers, R., \& Castelyns, V. (2011). LinkedIn and Facebook in Belgium: The influences and biases of social network sites in recruitment and selection procedures. Social Science Computer Review, 29(04), 437-448. DOI: 10.1177/0894439310386567.

Çitlak, O., Dörterler, M., \& Doğru, I. A. (2019). A survey on detecting spam accounts on Twitter network. Social Network Analysis and Mining, 09(01). ISSN 1869-5450. DOI: https://doi.org/10.1007/s13278-019-0582-x.

Davidsson, P., \& Honig, B. (2003). The role of social and human capital among nascent entrepreneurs. Journal of Business Venturing, 18(03), 301-331. DOI: 10.1016/S08839026(02)00097-6.

Donath, J. (2007). Signals in Social Supernets. Journal of Computer-Mediated Communication, 13(01), 231-251. DOI: https://doi.org/10.1111/j.1083-6101.2007.00394.X.

Ellison, N., Steinfield, C., \& Lampe, C. (2007). The Benefits of Facebook "Friends:" Social Capital and College Students' Use of Online Social Network Sites. Journal of Computer-Mediated Communication, 12(04), 1143-1168. DOI: https://doi.org/10.1111/j.1083-6101.2007.00367.x.

Fragoso, S. (2006). WTF a crazy Brazilian invasion. In F. Sudweeks \& H. Hrachovec (Eds.), Proceedings of CATaC 2006 (pp. 255-274). Murdoch, Australia: Murdoch University.

Franca, V., \& Pahor, M. (2012). The strength of the employer brand: influences and implications for recruiting. Journal of Marketing and Management, 03(01), 78-122.

Gajjala, R. (2007). Shifting frames: Race, ethnicity, and intercultural communication in online social networking and virtual work. In M. B. Hinner (Ed.), The Role of Communication in Business Transactions and Relationships (pp. 257-276). New York: Peter Lang.

Gavurová, B., Bačík, R., Fedorko, R., \& Nastišin, L. (2018). The Customer's Brand Experience in the Light of Selected Performance Indicators in the Social Media Environment. Journal of Competitiveness, 10(02), 72-84. DOI: https://doi.org/10.7441/joc.2018.02.05.

Gerard, J. G. (2012). Linking in With LinkedIn®: Three Exercises That Enhance Professional Social Networking and Career Building. Journal of Management Education, 36(06), 866-897. DOI: https://doi.org/10.1177/1052562911413464.

Hjorth, L., \& Kim, H. (2005). Being there and being here: Gendered customising of mobile $3 \mathrm{G}$ practices through a case study in Seoul. Convergence, 11(02), 49-55.

Kashi, K., Zheng, C., \& Molineux, J. (2016). Exploring factors driving social recruiting: The case of Australian organizations. Journal of Organizational Computing and Electronic Commerce, 26(03), 203-223. DOI: 10.1080/10919392.2016.1194055.

Kietzmann, J. H., Hermkens, K., McCarthy, I. P., \& Silvestre, B. S. (2011). Social media? Get serious! Understanding the functional building blocks of social media. Business Horizons, 54(03), 241-251. DOI: 10.1016/j.bushor.2011.01.005.

Kluemper, D. H., Mitra, A., \& Wang, S. (2016). Social Media use in HRM. Research in Personnel and Human Resources Management (Research in Personnel and Human Resources Management), Emerald Group Publishing Limited, 34(01), 153-207. ISSN 0742-7301. DOI: https://doi.org/10.1108/S0742-730120160000034011.

Kwok, L., \& Muñiz, A. (2021). Do job seekers' social media profiles affect hospitality managers' hiring decisions? A qualitative inquiry. Journal of Hospitality and Tourism Management, 46, 153-159. DOI: https://doi.org/10.1016/j.jhtm.2020.12.005. 
Landers, R. N., Schmidt, G. B., eds. (2016). Social Media in Employee Selection and Recruitment: Theory, Practice, and Current Challenges. Switzerland: Springer International. ISBN 978-3-319-29987-7. DOI: 10.1007/98-3-319-29989-1.

Lenhart, A., \& Madden, M. (2005). Teen content creators and consumers. Pew Internet and American Life Project, Washington, DC.

LinkedIn, 2019. Information about LinkedIn. [online]. Retrieved from https://press.linkedin.com/about-linkedin.

Melão, N., \& Reis, J. (2020). Using Social Networks in Personnel Selection: A Survey of Human Resource Professionals. In 15th Iberian Conference on Information Systems and Technologies (CISTI), 2020, 01-06. DOI: 10.23919/CISTI49556.2020.9140854.

Nyland, R., \& Near, C. (2007). Jesus is my friend: Religiosity as a mediating factor in Internet social networking use. A research paper presented at AEJMC Midwinter Conference, Reno, NV.

Papacharissi, Z. (2009). The virtual geographies of social networks: A comparative analysis of Facebook, LinkedIn and ASmallWorld. New Media \& Society, 11(01), 199-220. DOI: https://doi.org/10.1177/1461444808099577.

Rapanta, CH., \& Cantoni, L. (2017). The LinkedIn Endorsement Game: Why and How Professionals Attribute Skills to Others. Business and Professional Communication Quarterly, 80(04), 443-459. D0I: https://doi.org/10.1177/2329490616677044.

Rosen, D., Barnett, G. A., \&Kim, J. H. (2011). Social networks and online environments: when science and practice co-evolve. Social Network Analysis and Mining, 01(01), 27-42. DOI: https://doi.org/10.1007/s13278-010-0011-7.

Ruggieri, R., Savastano, M., Scalingi, A., Bala, D., \& D’Ascenzo, F. (2018). The impact of Digital Platforms on Business Models: an empirical investigation on innovative start-ups. Management \& Marketing. Challenges for the Knowledge Society, 13(04), 1210-1225. DOI: $10.2478 / \mathrm{mmcks}-2018-0032$.

Silva, C., Silva S., \& Martins, D. (2017). The LinkedIn Platform in Human Resources Recruitment. In: Sustainable Economic Growth, Education Excellence, and Innovation Management Through Vision 2020, 3942-3953.

Soulez, S., \& Guillot-Soulez, C. (2011). Marketing de recrutement et segmentation générationnelle : regard critique à partir d'un sous segment de la génération $Y$. Recherche et Applications en Marketing, 26(01), 39-57.

Srivastava, P., \& Bhatnagar, J. (2010). Employer brand for talent acquisition: an exploration towards its measurement. Vision, 14(01/02), 25-34.

Stokes, Y., Vandyk, A., Squires, J., Jacob, J.-D., \& Gifford, W. (2019). Using Facebook and LinkedIn to Recruit Nurses for an Online Survey. Western Journal of Nursing Research, 41(01), 96-110. DOI: https://doi.org/10.1177/0193945917740706.

Strenitzerová, M. (2016). HR marketing in terms of HR managers and employees application e-marketing tools. In: Proceedings of the International Scientific Conference on Marketing Identity 2016: Brands We Love Location: Slovak Acad Sci, Smolenice, 08 - 09 November.

The Chi-square test (2021). Information about Chi-square test. [online]. Retrieved from https://www.statisticssolutions.com/free-resources/directory-of-statisticalanalyses/chi-square/

Trusov, M., Bucklin, R. E., \& Pauwels, K. (2009). Effects of Word-of-Mouth Versus Traditional Marketing: Findings from an Internet Social Networking Site. Journal of Marketing, 73(01), 90-102. ISSN 0022-2429. DOI: https://doi.org/10.1509/jmkg.73.5.90.

Utz, S. (2016). Is LinkedIn making you more successful? The informational benefits derived from public social media. New Media \& Society, 18(11), 2685-2702. DOI: https://doi.org/10.1177/1461444815604143.

Vardarlier, P., \& Ozsahin, M. (2021). Digital Transformation of Human Resource Management: Social Media's Performance Effect. International Journal of Innovation and Technology Management, 18(03). DOI: https://doi.org/10.1142/S021987702150005X. 
Wasserman, S., \& Faust, K. (1994). Social network analysis: methods and applications. Cambridge: Cambridge University Press. ISBN 0-521-38707-8.

Wroblowská, Z. (2019). Personality Requirements for Ukrainian and Czech Managers Creating Brands as a Competitive Advantage. Journal of Competitiveness, 11(01), 152 167. DOI: https://doi.org/10.7441/joc.2019.01.10. 